\title{
Bella Italia: Specialized Pediatric Surgical Care in Italy
}

\author{
Giovanna Riccipetitoni ${ }^{1} \quad$ Piergiorgio Gamba ${ }^{2}$ Mario Lima ${ }^{3}$ Alessandro Inserra ${ }^{4}$ Ascanio Martino ${ }^{5}$ \\ Girolamo Mattioli $^{6}$ Gloria Pelizzo $^{7}$ Carmelo Romeo $^{8}$
}

${ }^{1}$ Department of Paediatric Surgery, V. Buzzi Children's Hospital, Milan, Italy

2 Department of Paediatric Surgery, University of Padua, Padua, Italy

${ }^{3}$ Department of Paediatric Surgery, University of Bologna,

Bologna, Italy

${ }^{4}$ Department of Surgery, Bambino Gesù Children's Hospital, Rome, Italy

${ }^{5}$ Department of Paediatric Surgery, Ospedali Riuniti, Ancona, Italy

${ }^{6}$ Department of Paediatric Surgery, G. Gaslini Children's Hospital,

University of Genoa, Genova, Italy

${ }^{7}$ Department of Paediatric Surgery, Paediatric Hospital of Palermo, Palermo, Italy

${ }^{8}$ Department of Paediatric Surgery, University of Messina,

Messina, Italy

Eur J Pediatr Surg 2017;27:422-428.
Address for correspondence Giovanna Riccipetitoni, MD, Via Castelvetro 32, 20154 Milano, Italy (e-mail: giovanna.riccipetitoni@asst-fbf-sacco.it).

\begin{abstract}
Keywords

- pediatric surgery

- pediatric care

- networks

Italian pediatric surgery has a long history, rich in events, places, and personalities that make it unique. Our first pediatric surgical unit dates back to the first half of the 19th century and its number has grown exponentially during the following decades, with a maximum flowering in the years after the second world war.

The rich history of pediatric surgery has not prevented it from facing important problems, such as the demographic crisis, underemployment of surgeons, and care of pediatric patients by adult specialists.

The attempt to find solutions to these problems has led to a great deal of efforts not only by pediatric surgeons, but also by the Italian government and institutions, with the implementation of ministerial plans that favor the specificity and growth of our discipline through thematic and territorial networks, through more effective training and specialization plans, the cooperation between the Directors of Pediatric Surgical Units for a better coordination of care, the participation in European networks, such as the recently created ERNs (European Reference Networks).

Many Italian pediatric surgeons are active in International Societies, as members or coordinators, in the design and management of multicenter studies and surveys and even in the creation of new international networks.

The Italian response to the demand for specialization and centralization involves knowledge sharing, large-scale cooperation, transversal between specialists and vertical with governmental authorities for a better and more effective care of pediatric patients.
\end{abstract}

(c) 2017 Georg Thieme Verlag KG Stuttgart · New York
DOI https://doi.org/ $10.1055 / \mathrm{s}-0037-1607027$. ISSN 0939-7248. 


\section{Introduction}

\section{Italy: Country of Saints, Poets, Navigators, and ... Pediatric Surgeons}

"del bel paese là dove 'l sì suona,"

- Dante, Divine Comedy: Inferno, Canto XXXIII, line 80

Of the fair land there where the 'Sì' doth sound,

- Dante, Divine Comedy: Inferno, translated by Henry Wadsworth Longfellow

"il bel paese

ch'Appennin parte e "l mar circonda e l'Alpe"

- Petrarch, Canzoniere, CXLVI, lines 13-14

"that fair country

the Apennines divide, and Alps and sea surround"

- Petrarch, Canzoniere, translation by A.S. Kline

Italy is a country with $60,589,445$ inhabitants ${ }^{1}$ and a density of $201.1 \mathrm{ab} / \mathrm{km}^{2}$; it is among the first 50 most densely inhabited states in the world. ${ }^{2}$

If we consider the data reported on the site of the Italian Society of Pediatric Surgery (SICP), our national territory has 61 pediatric surgery and/or urology units. ${ }^{3}$ The center deals with pediatric surgery for every million Italian citizens. Considering the number of specialists in pediatric surgery in Italy, the current members of SICP are approximately $200,{ }^{4}$ which would mean approximately 1 surgeon for every 300,000 inhabitants. These data place Italy among the countries with the largest number of specialists for our discipline, when compared with the general population.

These numbers reveal the amount of attention paid to pediatric care in Italy, where for decades, the pediatric patient has not been considered a "small adult," but a different individual, with unique characteristics and peculiar needs.

The Italian legislation is clear in this regard: "Children (0-17 years old) have the right to be admitted into a pediatric area, made up of structures, services, and staff appropriate to that age group" (Decree of the Regional Council of Lombardy; no. 6/38133; paragraph: "requirements and indicators for the accreditation of health facilities, maternal-infant, and pediatric area). ${ }^{5}$

But how does this widespread coverage influence the specialization of pediatric surgical care? The presence of so many surgeons may imply that they are not necessarily exposed to every pediatric surgical pathology, which by their nature are generally rare and often multiform, and require years of experience to be managed with the right level of expertise.

What is the awareness of the need to centralize pediatric surgical care in our country?

\section{History of Pediatric Surgery in Italy and the Italian Society of Pediatric Surgery}

It is imperative to remember our history, because those who have short memory deny the past and those who seek acceleration forget that every gestation takes its time and every season has its fruits.
The importance that pediatric care has always had in our country is evidenced by the history of Italian Pediatric Surgery.

Italy can boast the establishment of what is considered to be the first pediatric hospital in the world, the Innocenti Hospital, founded in Florence in 1495, where probably some of our predecessors performed some surgical procedures that had already been described by previous medical texts.

In modern times, surgical departments were opened in hospitals that were exclusively dedicated to children, such as the Regina Margherita Hospital in Turin (1845), the Bambino Gesù Children's Hospital in Rome (1869), the Burlo Garofolo Pediatric Institute in Trieste (1876), the Cesare Arrigo hospital in Alessandria (1886), the G. Salesi Hospital in Ancona (1900), the d Hospital in Florence (1904), and the Umberto I Hospital in Brescia (1907).

The first division of pediatric surgery instituted in a general hospital was that of the Galliera Hospital in Genoa, dating back to 1888 .

It is surprising to think that while for the birth of the Italian Republic, we had to wait until June 2, 1946, at the outbreak of second world war, Italy already accounted for 12 pediatric surgery facilities ${ }^{6}$ !

Less than 20 years after the proclamation of the Italian Republic, on February 24, 1963, the Italian Society of Pediatric Surgery (SICP) was established at the Department of Pediatric Surgery of the Hospital of Livorno. The first Steering Committee of SICP appointed Professor Pasquale Romualdi as the President and discussed a draft statute and draft regulation that still form the basis of all the activities of the Society itself.

The inaugural speech held by Professor Romualdi (Head of the Department of Pediatric Surgery at the Bambino Gesù Children's Hospital in Rome) during the opening ceremony of the first SICP Congress is still a manifesto of what pediatric surgery represents in Italy ${ }^{7}$ :

"The moral reasons that support the legitimacy of our Society's establishment are first and foremost those that are the basis of the separation of Paediatric Surgery as a specialty. [...] the consideration that in Paediatric Surgery everything is peculiar: the smallness of the anatomy, the difficulty in the diagnosis and instrumental manoeuvres for diagnostic purposes, and the scarcity of cases for the affections that are most difficult to recognize and cure [...]. And it is clear that only Paediatric Surgeons will be able to build a paediatric surgical pathology whose need is another reason to consider surgical paediatrics as "a whole" that must be subdivided as little as possible [...]. The constitution of the Society is a good opportunity and a good way to increase our scientific culture, to learn the best of the experience of each and every one of us, to know what else is going on and finally to get us to study."

The possibility to spread the teaching of pediatric surgery and the establishment of a pediatric surgical school, as hoped for by Professor Romualdi, materialized in 1966 when Professor Remigio Dòmini was appointed as the Adjunct Professor at the University of Bologna. He was the first Full Professor of Pediatric Surgery to start an independent clinical and scientific activity. $^{8}$

The history of Italian Pediatric Surgery is dotted with excellences that have changed the face of our discipline 
forever: we cannot forget the name of Professor Franco Soave from Genoa, who in the sixties, developed a revolutionary technique for correcting Hirschsprung's disease or that of Professor Carlo Alberto Montagnani, Head of the Pediatric Surgical Unit at Meyer's Hospital in Firenze since 1954, who after a period of study in the United States, introduced new techniques for the correction of bladder exstrophy.

As established by the SICP Official Statute and approved by the Members' Meeting on September 24, 2004, ${ }^{9}$ the Society "aims to promote the progress of the art and the surgical science in paediatrics, to promote and maintain the highest standards in the quality of surgical treatment delivered to children in Italy, to protect the prestige and interests of Paediatric Surgery and its practitioners, to facilitate the relationships and the exchange of ideas among Paediatric Surgeons." SICP represents the interests of Pediatric Surgery in the national scientific institutions; it collaborates with the Ministry of Health, Regions, Health Care, and Public Health Institutions. SICP also represents Italy in the European and world institutions of Pediatric Surgery.

The Society promotes professional and ongoing training for associates with annual training activities in Pediatric Surgery and meets in a National Congress that is held annually, with wide participation of the members and the most profound exchanges of experience and knowledge, also favoring the presence and awareness of young pediatric surgeons in the scientific discussion and the societal life.

\section{The Geography of Love}

We are extraordinarily attracted to this discipline, which is the only remaining general surgery, ranging from palatoschisis to imperforated anus, with the aim of correcting congenital malformations with great reliability and low mortality. This thing was not imaginable 20 years ago. New technologies (anesthesiology) with new operating and diagnostic techniques (radiology and minimally invasive surgery) have led to such an improvement.

From the second postwar period to the present, the number of pediatric surgical centers in Italy has tumultuously increased to reach the present number of 61 . However, these structures are not homogeneously distributed across the national territory: these are lacking in some regions (Molise, Basilicata), while numerous cities have more than one unit at their disposal, such as Turin (2), Milan (3), Florence (2), Rome (8), Naples (4), Bari (2), Foggia (2), Catania (2), and Palermo (2).

The growth of a number of specialized structures in our country was favored, especially in the decades from 1960 to 1980 , by some fundamental factors, such as the increase in the birth rate (the so-called demographic boom or baby boom) and the creation of techniques and technologies entirely peculiar to the pediatric age. These factors, combined with the love and attention that the Italian people have been dedicating to the pediatric age for centuries, have made our discipline growing for several years, before we had to face some issues that have threatened to undermine its growth and even to question its survival.

\section{Actual Interventions}

The problems that our discipline has been facing since the 1980s include mainly the major decline in births, dispersion of pediatric patients in adult surgical units, and underemployment of young pediatric surgeons.

\section{Fertility}

From 2009, all areas of the country have been affected by a significant decrease in birth rate. The recent birth rate is related to major changes in the female population in fertile age (conventionally fixed between 15 and 49 years). Italian women in this age group are, in fact, fewer. On one hand, the previously cited baby boomers were a result of reproductive experience, on the other hand, younger generations are less dependent on the effect of the so-called baby bust, that is the phase of a sharp decline in fertility (from the mid-1970s to the mid-1990s). Less fertile women inevitably lead to fewer births. Resident foreign women, who have partially filled the "voids," are aging. This effect is a consequence of the dynamics of immigration over the past decade: the boomers who made their entry or "emerged" following regularization have made a good part of their reproductive projects in our country over a decade, contributing significantly to the rise in fertility. The migratory dynamics have been mitigated by the crisis of recent years. Moreover, there are more foreign women workers. For these reasons, the contribution of foreign citizens to the birth rate of the resident population is slowly decreasing. The distribution of births by mother's age allows highlighting the shift of maternity to more advanced ages. About $8 \%$ of the births have a mother of at least 40 years of age, while the proportion of mothers under 25 years of age was $10.7 \%$ in 2014: high maternal age increases the risk of chromosomal abnormalities. ${ }^{10}$ This is a delicate topic and there is a national plan to catch the public attention on the issue of fertility and its protection aiming at increasing the population, protecting the fertility of men and women, and providing the right knowledge of procreation techniques.

\section{Appropriateness}

The Italian hospitalization data in pediatric age show higher values than in the rest of the world. Therefore, efforts have been made to ensure a proper use of resources and address the real needs of children and families. The first step is to guarantee true care continuity outside on the territory and avoid inappropriate hospital admissions.

The topic of appropriateness is one of the major challenges the National Health Service is dealing with. The Diagnosis Related Group System (DRG) was introduced in 1995 to promote operative efficiency and distribution equity but it led to an increment of inappropriate hospitalizations. In 2001 and 2017, essential assistance levels (LEA) were created to define services made available to citizens and rare disease indexes (ticket free). The new document identifies three aspects: public health and prevention, district assistance, and hospital assistance. Regions can provide additional levels of assistance according to their resources. 
The sanitary plan for the biennium 2003 to 2005 defines pediatric area as the "environment where the National Health Service takes care of the children's health, recognizing the peculiar features of neonates, infants, and adolescents." The New York International Agreement and the European Chart for hospitalized children are in force in Italy. As a consequence, children should always be treated in the pediatric departments. However, only $68 \%$ of patients between the age of 0 and 18 years are treated in pediatric wards. Considering adolescence (15-17 years), only $12.2 \%$ patients are treated in dedicated units, while $87.8 \%$ of patients remain with adult wards (often elderly) and are treated by doctors and nurses who are not trained for pediatric assistance. Efforts have been made to promote the development of pediatric hospitals that should represent the center of the specialized pediatric assistance, especially in the case of congenital chronic and rare diseases. Teaching, training, and research programs should be developed, as well. This project aims to develop many "all-inclusive" pediatric hospitals, with all the required pediatric medical and surgical specialties and facilities. In fact, a nonappropriate organization of the pediatric care does not provide a good level of assistance, and poor experience may increase the risk of adverse events. The law no. 135 (August 7, 2012) defines webs on the basis of the pathology. An organizational proposal is the "hub and spoke" model, where complex cases are referred in the "hubs," few hyperspecialized centers, integrated with peripheral "spokes."

The attention to the pediatric care is attested by the definition of Specific Pediatric Standards of Care in many pediatric specialties. An example is the SIAARTI/SARNePI document proposed by a Joint Commission. It defines the clinical standards useful to limit the risk of major complications during anesthesia (general and regional) and deep sedation in pediatric age. These standards are based on literature analysis and on the experience of members of the commission. ${ }^{11}$

During 2015 to 2016, the Ministry of Health defined the new standards for neonatal and pediatric medical and surgical assistance. ${ }^{12} \mathrm{~A}$ pediatric surgical unit is required for every 1.5 to 2.5 million people with a 24 hours activity, an emergency department, a neonatal intensive care unit (ICU) and a pediatric ICU. Day surgery activities can be performed by competent pediatric surgeons and pediatric anesthesiologists in general hospitals in patients older than 3 years of age. The presence of a neonatal ICU implies the existence of a pediatric surgery unit. As a consequence, regions redefined the number of complex units (UOC) and identified hub centers, equipped with pediatric ICU and specific expertise. For example, in Milan, with a metropolitan area of 3,900,000 inhabitants, the Decree 12/05/ 2017 identified two hub centers: the pediatric surgery unit at V. Buzzi Children's Hospital and the Fondazione IRCCS Ca' Granda Ospedale Maggiore Policlinico.

\section{Job Posts}

Another issue concerns the large number of pediatric surgery specialists who for years have not been able to find a job corresponding to their training, a phenomenon due to the disproportion that has existed for years between the training places and the job offer. This problem has, however, already been tackled by the creation of "aggregate schools": training centers have been pooled on a national basis, dramatically reducing the number of training posts that usually do not exceed 15 to 17 per year, significantly less than those available in the past decades. ${ }^{13}$ These new specialists will not struggle for years to find a job after their training, they will be immediately able to devote themselves to building their own career, and we believe that this will confer more solid foundations to our discipline.

Nevertheless, the educational program and training for "resident" pediatric surgeons in Italy has not yet reached the "best" European standards; recently, the Ministry of Education issued a new decree in conjunction with the Ministry of Health (Interministerial Decree no. 402, June 13, 2017) defining new standards for the accreditation of postgraduate schools. In particular, the minimum number of surgical procedures that have to be performed in each school by every postgraduate student has been defined. These new criteria will produce regional or interregional schools, including both university and nonuniversity large hospitals, with pediatric surgical units, involved in assistance and teaching, to assure an adequate and complete surgical and clinical experience to every trainee.

The solutions to the above-mentioned problems are difficult and largely fall outside the boundaries of pediatric surgery, affecting other areas, such as legislation, ethics, and social culture.

Nevertheless, the awareness of these issues among the Italian pediatric surgeons and their discussion on numerous occasions of encounter have made the institutional bodies aware of the need to take measures to make pediatric care increasingly specific and adapted to the needs of the child. Alongside this determination, there is a constant and growing enthusiasm for sharing knowledge, skills, and strengths of individual centers, designing multicenter studies and surveys, networks and collaborations between hospitals, creating guidelines that can make the professionals stronger in their everyday work, even if they have to deal with rare diseases and limited case series.

\section{From Ministerial Plans to Clinical Practice}

The Italian National Health Service (SSN), like other health services in other countries, is financed by general taxation, and therefore is affected by the current difficult financial context.

Despite this, it is still considered by the World Health Organization as one of the first in Europe and the world, based on three key indicators: improvement of the overall health status of the population, responses to the health and health care expectations of citizens, and the guarantee of the health services to the entire population.

In our system, great attention is given to the mother-child core and the pediatric care, as shown by the latest documents issued by the Ministry of Health, ${ }^{14}$ where the problem of decreasing fertility is addressed as a fundamental problem of the state. Health should be promoted before the birth of the individual, beginning from the preconception period and 
even earlier, in an optic of wider protection of reproductive health, preserving fertility with educational interventions already in the school period and early diagnostic interventions, as envisaged in the "National Fertility Plan."

Another issue addressed in the ministerial plans and that can be fundamental to our discipline is the establishment of thematic networks for the treatment of pathologies, to implement a fair distribution of the best clinical practices throughout the national territory, so as to allow all citizens a kind of proximity of access to the best procedures available.

As for the creation of networks, the model of the city of Milan is worth mentioning: the so-called RIMMI (Intercompany Milan Maternal-Infantile Network). ${ }^{15}$ It is an organizational model that connects, with formalized and coordinated modalities, professionals, and delivery facilities to improve the efficiency and fairness of the services rendered to the patients, also overcoming the limits and boundaries of current organizational models. The three pediatric surgery units of Milan actively participate in RIMMI, in a wideranging project that seeks to incorporate the various elements of excellence into a network that allows to share them all over the territory. The fundamental tools of RIMMI are communication, creation of the Welfare Diagnostic Therapeutic Paths (the so-called PDTA), and training.

Moreover, the heads of the pediatric surgical units and the departments have established a Consulta (Council of the Directors) to encourage cooperation processes, with a close interaction with the National and Regional Health Institutions.

Finally, the National Health Ministry emphasizes the importance of a constant and active participation in the ascendant phase of the European law through our participation in multiannual plans and collaborative initiatives (calls, joint actions, and joint initiatives).

\section{The European Model: European Reference Networks in Health Care: Moving Knowledge rather than Patients}

In March 2011, Directive 2011/24/EU on the application of patients' rights in cross-border health care was adopted. ${ }^{16}$ One particular area of cooperation that was identified in the directive was the development of the European Reference Networks (ERNs, Article 12). The development of multinational responses is especially needed for rare diseases, because of the lack of the "critical mass" in many member states, so that rare diseases can indeed be addressed more effectively in a broader European context. The functions and features of ERNs are to have knowledge and expertise to diagnose, follow-up, and treat patients with evidence of good outcomes, follow a multidisciplinary approach, produce good practice guidelines, make a contribution to research, organize teaching and training activities, and collaborate closely with other centers of expertise and networks at national and international levels. ${ }^{17}$ The European Commission (EC) has to ensure that ERNs have the necessary requirements. Most reference networks focus on particular diseases or conditions, i.e., rare conditions, chronic conditions, critical conditions (e.g., neonatal intensive care, burns, transplants, etc.).
The most relevant ERN for our discipline is ERNICA, the European Reference Network on rare Inherited and Congenital Anomalies that mainly covers rare inherited and congenital digestive disorders. Congenital malformations and diseases included in ERNICA share early manifestation in life at pediatric age, need for multidisciplinary care, and long-term followup. Low incidence of these disorders and the fact that these can often be diagnosed before birth require a joined up approach for treatment and a shared experience for patient support.

The first 24 ERNs were launched in 2017, involving more than 900 highly specialized healthcare units from over 300 hospitals in 26-member states. ${ }^{18}$ Numerous Italian centers are part of the ERNs, proving Italy's willingness to contribute to the sharing of knowledge, especially in areas where it is more difficult to have extensive experience due to the reduced incidence of diseases and hence the reduced number of patients.

At the national level, Italy already has a multi-year experience in creating healthcare networks. Centers of expertise and reference networks started to emerge in the mid-1990s, similar to other European countries, in an effort by policy makers and practitioners to improve the safety and quality of treatments. The main areas where reference centers were identified and networks created were rare diseases, complex procedures (transplants), and research-oriented activities (centers where trials, innovative practices, and latest technology should be introduced). Two important examples are the network for the treatment of rare pathologies (RNMR-Rete Nazionale Malattie Rare), whose diagnosis and treatment are very important also in our discipline and the National Transplant Centre (CNT-Centro Nazionale Trapianti) that controls and coordinates transplants in Italy.

\section{Italian Promoters of Teamwork}

Perhaps in Italy, we have too many centers that deal with pediatric surgery. Another possibility is that we have too many surgeons for too few patients; this may be detrimental to the specialization and excellence of care.

However, it must be admitted that many Italian pediatric surgeons are major advocates of knowledge sharing and have been at the forefront in promoting surveys, multicenter studies, teams, and networks to overcome the limits of each center.

For example, numerous outstanding research have been published in the past years on relevant topics, such as diagnosis and treatment of neuroblastoma by the Italian GICOP (Pediatric Oncologic Surgery Study Group). ${ }^{19,20}$ The topic of pediatric tumors has led to the formation of one of the first collaborative networks in Italy, established by Professor Maurizio Guglielmi from Padua more than 30 years ago, which now includes the most relevant centers for oncologic multidisciplinary care and play an educational and supportive role for all the Italian pediatric surgical community. Anorectal malformations have been extensively studied by Italian and international specialists within the anorectal malformation network (ARM-Net) consortium $^{21}$; Italian surgeons have been leading researchers in surveys promoted by the European Pediatric Surgeons' Association, ${ }^{22}$ others are constantly promoting interesting national surveys on minimally-invasive treatment of different 
conditions. $^{23}$ Other important European multicenter studies have been coordinated by Italian centers, for example on minimal access adrenal surgery for adrenal pathologies, ${ }^{24}$ laparoscopic treatment of pancreatic tumors, ${ }^{25}$ the surgical correction technique of congenital Morgagni diaphragmatic hernia ${ }^{26}$; finally, some important topics have been analyzed by multicenter studies on a national basis, such as bariatric procedures, ${ }^{27}$ management of pediatric ovarian torsion and its recurrence, ${ }^{28}$ phenotype-genotype correlation in Currarino syndrome. $^{29}$

In 2017, the first International Network of Pediatric Airway Teams (INPAT) was created, thanks to the initiative of the Otolaryngology and Pediatric Surgery groups of G. Gaslini Children's Hospital of Genoa. The first INPAT meeting was held in Genoa last March and was a great success, gathering specialists from all over the world. The idea and the rationale of this network should inspire all of us in every field we work: "If the team work has been recognized as the best way to face difficult challenges as airway anomalies in children, we guess that the association and cooperation of the Pediatric Airway Teams can have a tremendous positive impact on the clinical outcome of these patients." 30

Minimally-invasive surgery (MIS) was first diffused in Italy by Professor Giovanni Esposito, from Naples, who founded the Italian Society of Infantile Videosurgery (SIVI) in 1995; starting from that moment, a group of pioneers pledged to spread MIS in Italy, where at present, it is extensively performed in all the pediatric surgical units; some centers played a primary role in launching educational university programs, such as the second level Master in MIS of Bologna University and the educational courses in Naples.

Pediatric urology in Italy is traditionally performed by pediatric surgeons as in many European countries; the educational and training pediatric surgical programs are constructed to develop special skills in the urological field, which represent a significant percentage of the pediatric surgical activity.

Moreover, Italian pediatric surgeons seek to treat most of the surgical diseases of pediatric age: thoracic, digestive, hepatobiliopancreatic, urological, vascular, oncological, and plastic, mainly through hyperspecialized qualifying pathways that try to keep every field within the discipline, avoiding to resort to adult specialists.

The current year has given exceptional opportunities to Italian pediatric surgery, since the Presidencies of the European Pediatric Surgeons' Association (EUPSA), the European Society of Pediatric Endoscopic Surgeons (ESPES), and the Surgical Oncology Group of the SIOP (International Society of Pediatric Oncology) have been conferred on three Italian colleagues (Giovanna Riccipetitoni from Milan, Ciro Esposito from Naples, and Giovanni Cecchetto from Padua, respectively), giving new enthusiasm and vitality to the life of our discipline.

Speaking of specialization, centralization, excellence, we must never forget that the purpose of our daily activity is the well-being of our pediatric patients, the continuous improvement of the care we offer them and their quality of life.

In Italy, we still have a long way to go, but the brief panoramic view we have presented shows how our pediatric surgery fights every day to improve itself and its profes- sionals, alongside the authorities, the laws and families, to offer more to our children, who will be our future.

"The aim of paediatric surgery is to set a standard, not to create a monopoly."

Sir Denis Browne

Conflict of Interest

None.

\section{References}

1 Bilancio demografico mensile. Available at: demo.istat.it. Accessed April 28, 2017

2 Index mundi. Population Density-World. Available at : http:// www.indexmundi.com $/ \mathrm{map} / ? \mathrm{t}=0 \& \mathrm{v}=21000 \& \mathrm{r}=\mathrm{xx} \& \mathrm{l}=\mathrm{it}$

3 Italian Society of Pediatric Surgery. Available at: http://www. chped.it/?page_id=33

4 Italian Society of Pediatric Surgery. Available at: http://www. chped.it/?page_id=31

5 DELIBERAZIONE N. VI/38133 del 6 agosto 1998

6 Parigi GB, La chirurgia pediatrica in Italia: un problema da risolvere. From the archives of the Società Italiana di Chirurgia Pediatrica, Courtesy of Prof. Gian Battista Parigi, MD, FEBPS, President of the Center for International Cooperation, University of Pavia, Italy

7 Italian Society of Pediatric Surgery. Available at: http://www.chped.it/

8 Remigio Dòmini. Introductive Speech during the 33th SICP Congress, Bologna, 26th September 1998

9 Italian Society of Pediatric Surgery. Available at: http://www. chped.it/?page_id=156

10 Zhang XH, Qiu LQ Ye YH, Xu J. Chromosomal abnormalities: subgroup analysis by maternal age and perinatal features in zhejiang province of China, 2011-2015. Ital J Pediatr 2017;43(01):47

11 Edoardo C, Nicola D, Laura L, et al. Standard Clinico-Organizzativi SIAARTI-SARNePI per l'anestesia in età pediatrica. SIAARTI Rome, 31 January 2017

12 Ministero della Salute. Linee di indirizzo per la promozione e il miglioramento della qualità, della sicurezza e dell'appropriatezza degli interventi assistenziali in area pediatrico-adolescenziale". Rome, October 31, 2016

13 Allegato 2 al Decreto MIUR 20.05.2016 n.313 come rettificato dal D.M. 23.05.2016 n.319

14 Official guidelines for the year 2017, Ministry of Health of the Italian Republic, signed on September 23, 2016

15 D.d.g. 18 marzo 2016 - n. 1988. Rete interaziendale Milano Materno-Infantile (R.I.M.M.I.). Bollettino Ufficiale Regione Lombardia, Serie Ordinaria n. 12-Venerdì 25 marzo 2016

16 EUR-Lex. Access to European Union Law. Available at: http://eurlex.europa.eu/legal-content/IT/TXT/?uri=CELEX\%3A32011L0024

17 WHO. Building European Reference Networks in Health CareExploring concepts and national practices in the European Union. Palm W, Glinos IA, Rechel B, Garel P, Busse R, Figueras J, eds. European Observatory on Health Systems and Policies. Copenhagen, Denmark: World Health Organization; 2013

18 European Reference Networks. Working for patients with rare, low-prevalence and complex diseases. Share. Care. Cure. Available at: https://ec.europa.eu/health/sites/health/files/ern/docs/ 2017_brochure_en.pdf

19 Pio L, Avanzini S, Mattioli G, et al. Perioperative management of hypertensive neuroblastoma: A study from the Italian Group of Pediatric Surgical Oncologists (GICOP). J Pediatr Surg 2017. Doi: 10.1016/j.jpedsurg.2017.06.027

20 Avanzini S, Faticato MG, Crocoli A, et al. Comparative retrospective study on the modalities of biopsying peripheral neuroblastic tumors: a report from the Italian Pediatric Surgical Oncology Group (GICOP). Pediatr Blood Cancer 2017;64(5). Doi: 10.1002/ pbc. 26284 
428 Specialized Pediatric Surgical Care in Italy Riccipetitoni et al.

21 ARM net. Available at: http://www.arm-net.eu/index.php/ publications

22 Morini F, Zani A, Conforti A, et al. Current Management of Congenital Pulmonary Airway Malformations: a "European Pediatric Surgeons' Association” Survey. Eur J Pediatr Surg 2017. Doi: $10.1055 / \mathrm{s}-0037-1604020$

23 Chiarenza SF, Bleve C, Caione P, et al. Minimally invasive treatment of pediatric extrinsic ureteropelvic junction obstruction by crossing polar vessels: is vascular hitching a definitive solution? report of a multicenter survey. J Laparoendosc Adv Surg Tech A 2017

24 Fascetti-Leon F, Scotton G, Pio L, et al. Minimally invasive resection of adrenal masses in infants and children: results of a European multi-center survey. Surg Endosc 2017. Doi: 10.1007/ s00464-017-5506-0

25 Esposito C, De Lagausie P, Escolino M, et al. Laparoscopic resection of pancreatic tumors in children: results of a multicentric survey.J Laparoendosc Adv Surg Tech A 2017;27(05):533-538
26 Esposito C, Escolino M, Varlet F, et al. Technical standardization of laparoscopic repair of Morgagni diaphragmatic hernia in children: results of a multicentric survey on 43 patients. Surg Endosc 2017;31(08):3320-3325

27 Castellani RL, Toppino M, Favretti F, Camoglio FS, Zampieri N. National survey for bariatric procedures in adolescent: Long time follow-up. J Pediatr Surg 2017. Doi: 10.1016/j.jpedsurg.2017.03.005

28 Bertozzi M, Esposito C, Vella C, et al. Pediatric ovarian torsion and its recurrence: A multicenter study. J Pediatr Adolesc Gynecol 2017;30(03):413-417

29 Costanzo S, Spaccini L, Pio L, et al. Currarino syndrome: does the presence of a genetic anomaly correlate with a more severe phenotype? A multicentre study. J Pediatr Surg 2017. Doi: 10.1016/j.jpedsurg.2017.06.012

30 INPAT. International Network of Pediatric Airway Teams. Available at: http://www.inpat.cisef.org/inpat.php 